\title{
Correction to: The learning curve of endoscopic thyroid surgery for papillary thyroid microcarcinoma: CUSUM analysis of a single surgeon's experience
}

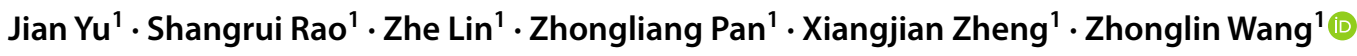 \\ Published online: 5 January 2022 \\ (c) The Author(s) 2022
}

Correction to: Surgical Endoscopy (2019) 33:1284-1289

https://doi.org/10.1007/s00464-018-6410-y

This article has been updated to correct Affiliation 1.

Publisher's Note Springer Nature remains neutral with regard to jurisdictional claims in published maps and institutional affiliations.

The original article can be found online at https://doi.org/10.1007/ s00464-018-6410-y.

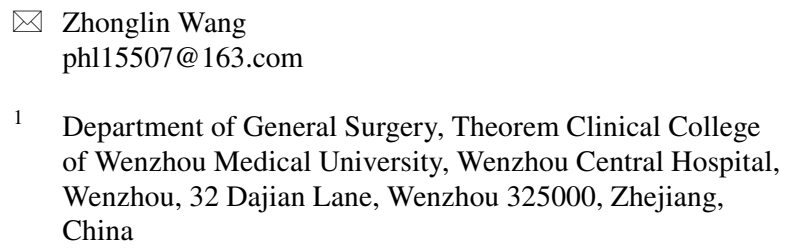

